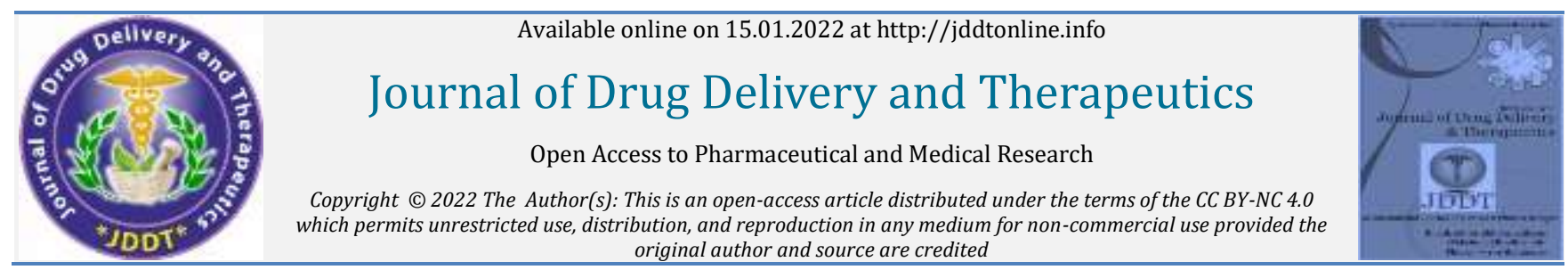

Open 1 Access Full Text Article (c) (1) (5) Research Article

\title{
Formulation and Evaluation of Essential Oil Encapsulated Mosquito Repellent Gel
}

\author{
Pramod Kumar*1, Rohit Kumar Bijauliya ${ }^{2}$, Balbir Singh², Priti Yadav ${ }^{1}$ and Wasim Ahmed Khan ${ }^{3}$ \\ ${ }^{1}$ Department of Pharmacy, Rameshwaram Institute of Technology and Management, Lucknow-227202, India \\ ${ }^{2}$ BIU College of Pharmacy, Bareilly International University, Bareilly-243006, Uttar Pradesh, India \\ ${ }^{3}$ Modern College of Pharmacy, Kochhabhawar, Jhansi-284128, Uttar Pradesh, India
}

\begin{tabular}{ll}
\hline Article Info: & \\
& Article History: \\
& $\begin{array}{l}\text { Received } 12 \text { November } 2021 \\
\text { Accepted 21 December } 2021\end{array}$ \\
& Published 15 January 2022
\end{tabular}

\section{Cite this article as:}

Kumar P, Bijauliya RK, Singh B, Yadav P, Khan WA, Formulation and Evaluation of Essential Oil Encapsulated Mosquito Repellent Gel, Journal of Drug Delivery and Therapeutics. 2022; 12(1):23-29

DOI: http://dx.doi.org/10.22270/jddt.v12i1.5265

*Address for Correspondence:

Pramod Kumar, Research Scholar, Department of

Pharmacy, Rameshwaram Institute of Technology and

Management,

Lucknow, Uttar Pradesh, India

\section{Abstract}

Mosquitoes can be found in almost every country. Many mosquito repellents have been introduced to the market in order to combat them. The mosquitos, on the other hand, developed a resistance to them. Not only that, but users are experiencing a variety of known and unknown negative side effects. As a result, a poly herbal insect repellent gel has been developed in an attempt to give dependable, long-lasting, and full protection from mosquito bites by destroying them. Three essential oils were included in the formulation of the mosquito repellent gel, as well as polymers such as tween 80 , span 20, Carbopol 934, and triethanolamine. They were assessed based on their actions. Spreadibility, viscosity, swelling index, and mosquito repellent activity were used to evaluate the prepared mosquito repellent gel. As acceptance criterion, all parameters received favorable responses. The rheological study and mosquito repellent activity are highly correlated. Although the results of the current trials are promising, there is still room for more pharmacokinetic research.

Keywords: Essential Oil, Emulsion Formulations, Gel, Mosquito Repellent Activity

\section{INTRODUCTION:}

Mosquitoes are among the most vexing bloodsucking insects that plague humans 1, 2. Several mosquito species from the genera Anopheles, Culex, and Aedes serve as vectors for pathogens associated with diseases such as Dengue fever, Malaria, Yellow fever, Japanese encephalitis, and others 3. Mosquitoes alone transmit diseases to over 700 million people, and over one million people die each year around the world. Four and five as a result, mosquito control is a major public health concern globally 4,5 .

Because the majority of mosquito repellent products and devices on the market have been reported to be harmful to humans, the goal of this study is to develop an effective essential oil-based mosquito repellent gel.

\section{MATERIALS AND METHODS:}

The selection of the plants was based on their availability as raw materials, scientific evidence and folkloric use as mosquito repellents. The essential were procured from local market of Lucknow.

\section{A) Preparation of Emulsion:}

1) Firstly, take a $100 \mathrm{ml}$ beaker and add $0.5 \mathrm{ml}$ of lemon grass oil, $0.5 \mathrm{ml}$ camphor oil and $0.5 \mathrm{ml}$ eucalyptus oil.

2) Then add $1 \mathrm{ml}$ of span 20 in beaker and shake for few minutes.

3) Then taken another beaker (II) and add $1.5 \mathrm{ml}$ of tween 80 and then add $3.5 \mathrm{ml}$ distilled water in beaker (II) and shake for few minutes

4) Then beaker (II) sample add dropwise in beaker (I) and shake till the until clear transparent emulsion are not obtained.

\section{B) Preparation of Gel Base:}

1) Firstly, take $500 \mathrm{mg}$ of Carbopol 934 was taken in a 500 $\mathrm{ml}$ beaker and $40 \mathrm{ml}$ distilled water was added into the beaker.

2) Now the mixture was kept on mechanical stirrer for 1 hours.

3) Now add 2-3 drops of triethanolamine was added to clear and transparent gel was formed. 
C) Preparation of Mosquito Repellent Gel: Firstly, take the prepared gel $40.5 \mathrm{gm}$ in $500 \mathrm{ml}$ beaker and add prepared emulsion $7.5 \mathrm{ml}$ then volume make up $50 \mathrm{gm}$ with distilled water and stirrer for few minutes till a clear transparent gel was formed. Finally, the gel was placed into a plastic container, allowing for testing 5 .

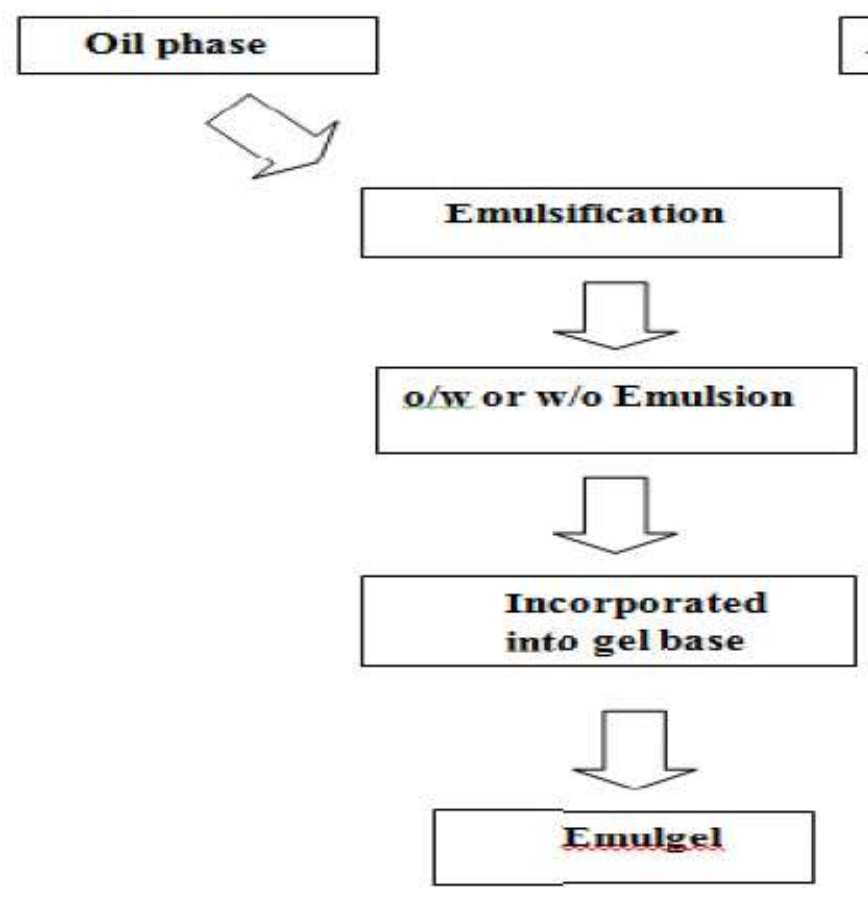

Flow Chart 1: Formulation of Emulgel

Evaluation of Gels: Gels were evaluated for their clarity, $\mathrm{pH}$, viscosity, spreadability, by using standard procedure All studies were carried out in triplicate and average values were reported 6 .

A) Clarity: Visual assessment of several formulations against a black and white background was used to grade their clarity, which was graded as follows: turbid: + , clear: ++ , very clear (glassy):.$+++{ }^{7}$

B) pH: $2.5 \mathrm{~g}$ of gel was weighed and mixed with $25 \mathrm{~mL}$ of distilled water. A digital $\mathrm{pH}$ meter was used to determine the dispersion's pH. (Systronics pH system 362) ${ }^{8}$.

C) Homogeneity: After the gels had been placed in the container, they were visually inspected for homogeneity and any aggregates 6 .

D) Spreadability: It was determined by wooden block and glass slide apparatus and for the determination of spreadibility excess of sample was applied in between two glass slides and was compressed to uniform thickness by placing $1000 \mathrm{gm}$ weight for 5 minutes. Weight (50 gm) was added to pan. The time required to separate the two slides, i.e. the time in which the upper glass slide moves over the lower plates was taken as measure of spreadability (S) 6 . This formula was used to calculate spreadibility:

$\mathrm{S}=\mathrm{ML} / \mathrm{T}$

Where, $\mathrm{S}=$ Spreadability, $\mathrm{M}=$ Weight tide to upper slide,

$\mathrm{L}=$ Length moved on the glass slide, $\mathrm{T}=$ Time taken to separate the slide completely from each other

E) Viscosity Measurement: The gels' viscosity was measured with a Brookfield Viscometer and a tiny sample adaptor with the spindle number SC4-18/13R. A toque ranging from $10 \%$ to $100 \%$ was applied to the gel. The viscosity was calculated using the software Rheocal. ${ }^{7}$
F) Extrudability: The Pfizer harness tester was used to conduct the extrudability test. In an aluminum tube, 15 gram of gel was placed. The plunger was adjusted to adequately grasp the tube. For 30 seconds, a pressure of $1 \mathrm{~kg} / \mathrm{cm}^{2}$ was applied. The amount of gel extruded was measured and weighed. The operation was done three times at equal distances along the tube. Test was carried out in triplicates 7 .

F) Swelling Index: Using 2 gm of dermal polyherbal gel in a beaker containing $10 \mathrm{ml}$ distilled water, the swelling index of the gel was calculated. The swollen formulation was removed from the beaker and placed on a petridish after one hour (CEVC G, 2004). The swelling index was calculated using the following formula:

$$
\text { Swelling index }(\mathrm{Si})=\mathrm{W}_{\mathrm{t}}-\mathrm{W}_{\mathrm{o}} / \mathrm{W}_{\mathrm{t}} \times 100
$$

Where, $\mathrm{Wt}=$ weight of swollen at $\mathrm{t}$ time, $\mathrm{Wo}=$ original weight of gel at zero time.

G) Mosquito Repellant Activity: Initially, volunteers' forearms were carefully cleansed with soap and dried completely. The control was maintained within the mosquito cage using the left arm. Within 30 seconds, the frequency of the vector settled on the forearm. The investigation began when the mosquitoes landed in groups of more than ten. After 30 seconds, the arm was carefully withdrawn from the mosquito cage, and the right arm was wiped with mosquito repellent gel formulation, and the trial was repeated after $30,60,120,240$, and 480 minutes, in the same manner. The number of mosquitos that landed was counted and compared to a positive control group (Transfluthrin) ${ }^{9}$. The study was performed in triplicate manner.

H) Accelerated Stability Studies: The For 90 days, the improved formulation was exposed to accelerated stability $\left(40^{\circ} \mathrm{C} 2^{\circ} \mathrm{C}\right.$ temperature; 75 percent 5 percent relative humidity). The prepared gel formulation was stored in a PVC 
container with a black foil covering. Physical appearance, $\mathrm{pH}$, readability, viscosity, and extrudability were considered as key characteristics 10 .

\section{RESULTS AND DISCUSSION}

\section{Physical Appearance of Essential Oil:}

\section{Lemon grass oil}

- Appearance: Pale yellow to yellow clear liquid

- Colour: Pale yellow to yellow

- Odour: Odourless

- Taste: Pungent

\section{Camphor oil}

- Appearance: White Liquid
- Colour: Fragrant and Penetrating

- Odour: White Translucent crystal

\section{Eucalyptus oil}

- Appearance: Pale yellow Liquid-oil

- Odour: Camphoraceous odour

- Colour: Colorless to pale yellow liquid

- Taste: Pungent, spicy, cooling taste

FTIR Study: FTIR Spectra of Eucalyptus oil, Camphor oil and Lemongrass oil in their pure form was recorded. The FTIR spectrum of essential oil are shown in figure 1, 2 and 3 . The IR spectrum interpretation of essential oil (Eucalyptus oil, Camphor oil and Lemongrass oil) is given in Table 1, 2, 3 .

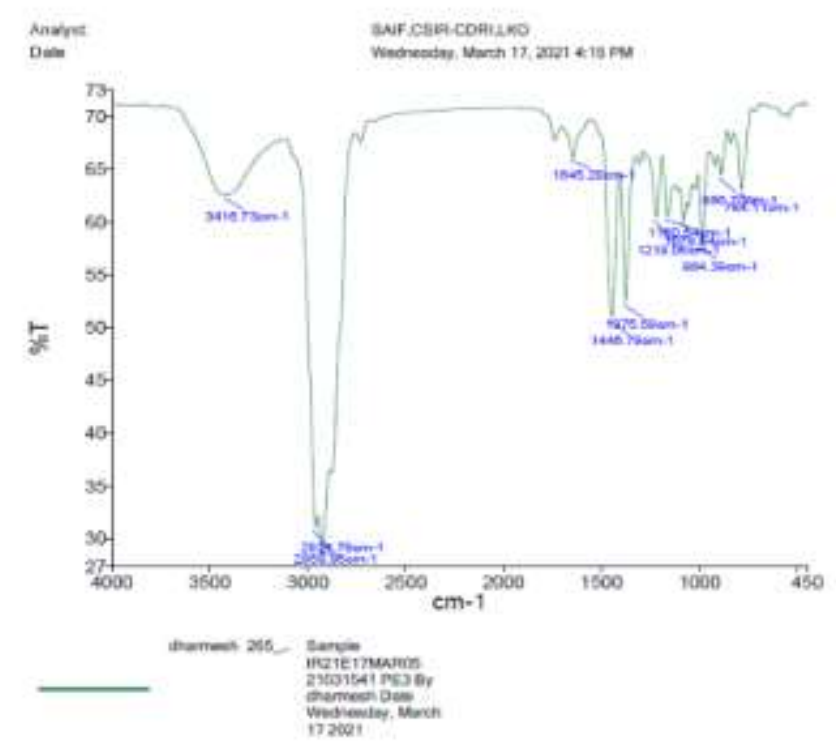

Figure 1: FTIR of Eucalyptus oil

Table 1: Interpretation of FTIR of Eucalyptus oil

\begin{tabular}{|l|l|l|}
\hline S. No. & Frequency $\left(\mathbf{c m}^{-1}\right)$ & Assignments \\
\hline 1 & 3416.73 & - OH Stretching \\
\hline 2 & 2959.95 & $-\mathrm{CH}_{2}$ asymmetric stretching \\
\hline 3 & 1645.20 & C-C binding with aromatic ring stretching \\
\hline 4 & 1446.78 & Alkene type stretching \\
\hline 5 & 1375.59 & C=C stretch \\
\hline 6 & 784.11 & C-OH out of plane bending \\
\hline
\end{tabular}

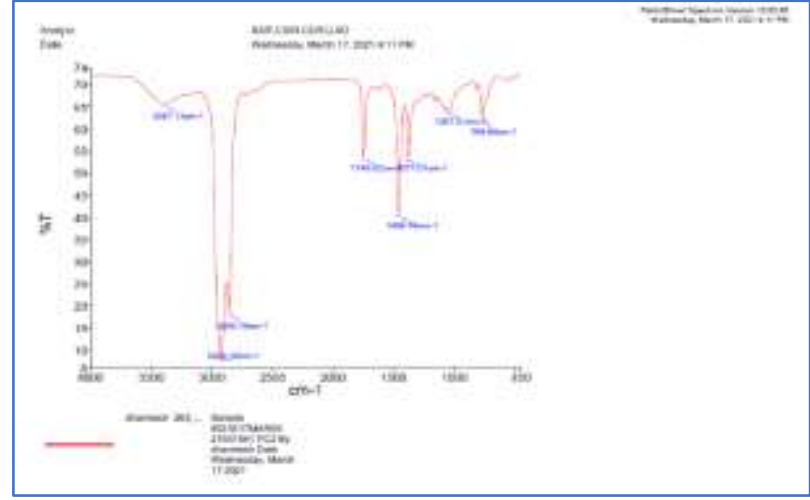

Figure 2: FTIR of Camphor oil 
Table 2: Interpretation of FTIR of Camphor

\begin{tabular}{|l|l|l|}
\hline S. No. & Frequency $\mathbf{( c m}^{-1} \mathbf{)}$ & Assignments \\
\hline 1 & 3387.13 & $-\mathrm{OH}$ Stretching \\
\hline 2 & 2924.28 & $-\mathrm{CH}_{2}$ asymmetric stretching \\
\hline 3 & 1746.62 & $\begin{array}{l}\text { C-C binding with aromatic } \\
\text { ring stretching }\end{array}$ \\
\hline 4 & 1458.79 & Alkene type stretching \\
\hline 5 & 1377.01 & C=C stretch \\
\hline 6 & 766.88 & C-OH out of plane bending \\
\hline
\end{tabular}

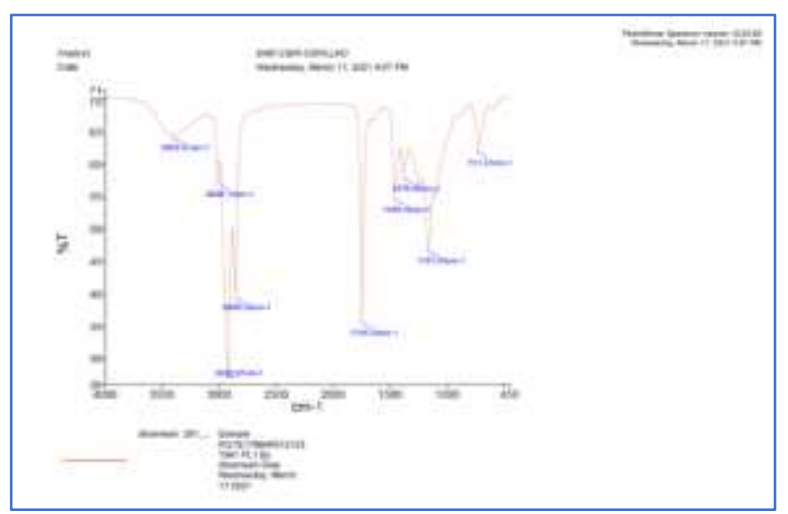

Figure 3: FTIR of Lemongrass

Table 3: Interpretation of FTIR of Lemongrass oil

\begin{tabular}{|l|l|l|}
\hline S. No. & Frequency $\mathbf{( c m}^{-1} \mathbf{)}$ & Assignments \\
\hline 1 & 3403.01 & - OH Stretching \\
\hline 2 & 2926.07 & $\begin{array}{l}-\mathrm{CH}_{2} \text { asymmetric } \\
\text { stretching }\end{array}$ \\
\hline 3 & 1745.34 & $\begin{array}{l}\text { C-C binding with aromatic } \\
\text { ring stretching }\end{array}$ \\
\hline 4 & 1458.49 & Alkene type stretching \\
\hline 5 & 1161.94 & C=C stretch \\
\hline 6 & 721.47 & C-OH out of plane bending \\
\hline
\end{tabular}

FTIR spectrum showed characteristic peaks and bands which are representing the presence of functional groups which help in the identification of the drug. These bending and stretching in the FTIR spectrum expressed the structure of camphor oil, lemon grass oil and eucalyptus oil and the presence of functional groups in the active moiety which would be responsible for the characteristics of the drug, and it would also act as a helping tool for the identification of camphor oil, lemon grass oil and eucalyptus oil.

Compatibility Study of Essential Oil: Principle peaks of essential oil were observed retained; broadening of peaks may be due to overlapping of peaks of polymer system. From the spectral study it was observed that the FTIR spectrum of pure essential oil (camphor oil, eucalyptus oil, lemongrass oil) there was no significant change in the peaks essential oil polymer mixture. Therefore, it can be inferred that there was no specific interaction observed between the essential oil and the polymers.

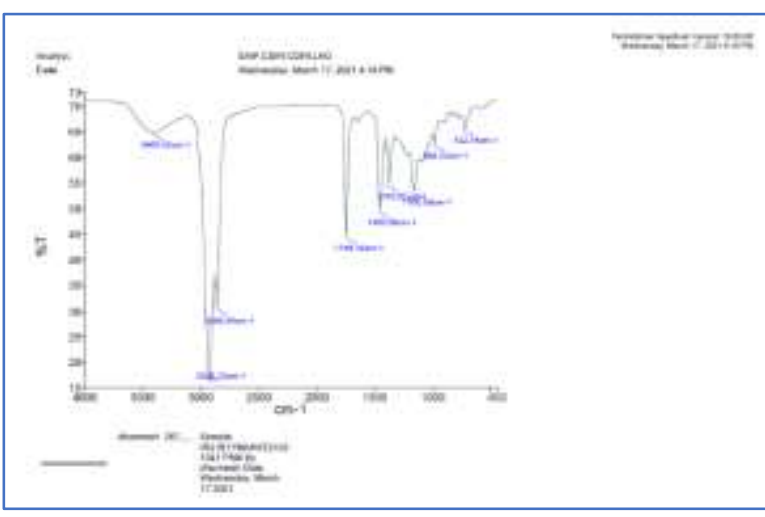

Figure 4: FTIR of mixture of Essential oils

Table 4: Interpretation of FTIR of mixture of Essential oils

\begin{tabular}{|l|l|l|}
\hline S. No. & Frequency $\mathbf{( c m}^{-1} \mathbf{)}$ & Assignments \\
\hline 1 & 3405.42 & - OH Stretching \\
\hline 2 & 2925.07 & $-\mathrm{CH}_{2}$ asymmetric stretching \\
\hline 3 & 1746.18 & $\begin{array}{l}\text { C-C binding with aromatic } \\
\text { ring stretching }\end{array}$ \\
\hline 4 & 1376.62 & Alkene type stretching \\
\hline 5 & 1160.56 & C=C stretch \\
\hline 6 & 722.75 & C-OH out of plane bending \\
\hline
\end{tabular}

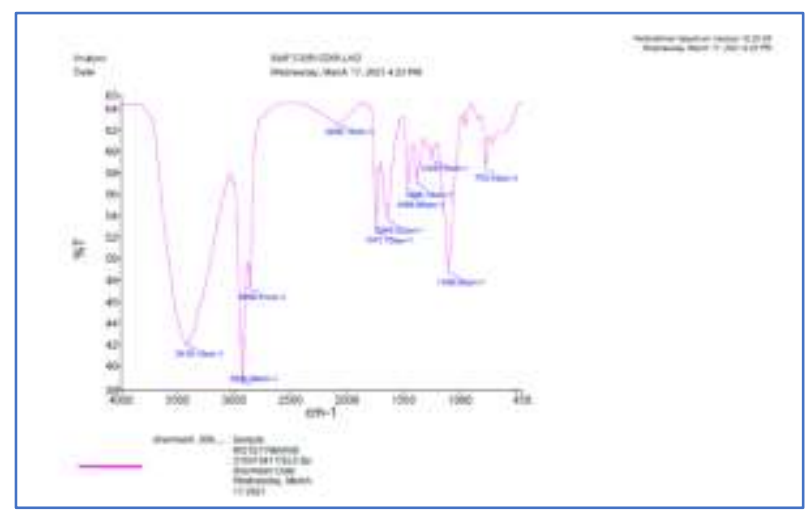

Figure 5: FTIR Study of emulsion

Table 5: Interpretation of FTIR of emulsion

\begin{tabular}{|l|l|l|}
\hline S. No. & Frequency $\mathbf{( c m}^{-1} \mathbf{)}$ & Assignments \\
\hline 1 & 3416.18 & - OH Stretching \\
\hline 2 & 2858.51 & $-\mathrm{CH}_{2}$ asymmetric stretching \\
\hline 3 & 2086.16 & $\begin{array}{l}\text { C-C binding with aromatic } \\
\text { ring stretching }\end{array}$ \\
\hline 4 & 1380.18 & Alkene type stretching \\
\hline 5 & 1248.78 & C=C stretch \\
\hline 6 & 770.43 & C-OH out of plane bending \\
\hline
\end{tabular}

\section{FORMULATION DEVELOPMENT:}

A) Preparation of Emulsion: Various types of essential oil was used for the preparation of emulsion. List of ingredient show Table 6. 
Table 6: Formulation of Emulsion 3\%

\begin{tabular}{|l|l|l|}
\hline S. No. & Chemicals & Quantity \\
\hline 1 & Lemongrass oil & $0.5 \mathrm{ml}$ \\
\hline 2 & Camphor oil & $0.5 \mathrm{ml}$ \\
\hline 3 & Eucalyptus oil & $0.5 \mathrm{ml}$ \\
\hline 4 & Tween 80 & $1.5 \mathrm{ml}$ \\
\hline 5 & Span 20 & $1 \mathrm{ml}$ \\
\hline 6 & Distilled Water & $3.5 \mathrm{ml}$ \\
\hline
\end{tabular}

B) Preparation of Gel Base: Formulation of gel base with the Carbopol and triethanolamine for the development of mosquito repellent gel.

Table 7: Formulation of Gel Base I

\begin{tabular}{|l|l|l|}
\hline S. No. & Chemicals & Quantity \\
\hline 1 & Carbopol 934 & 0.5 gm \\
\hline 2 & Triethanolamine & Few drops \\
\hline 3 & Distilled water & $40 \mathrm{ml}$ \\
\hline
\end{tabular}

Table 8: Formulation of Gel Base II

\begin{tabular}{|l|l|l|}
\hline S. No. & Chemicals & Quantity \\
\hline 1 & Carbopol 934 & $1.0 \mathrm{gm}$ \\
\hline 2 & Triethanolamine & Few drops \\
\hline 3 & Distilled water & $40 \mathrm{ml}$ \\
\hline
\end{tabular}

Table 9: Formulation of Gel Base III

\begin{tabular}{|l|l|l|}
\hline S. No. & Chemicals & Quantity \\
\hline 1 & Carbopol 934 & $1.5 \mathrm{gm}$ \\
\hline 2 & Triethanolamine & Few drops \\
\hline 3 & Distilled water & $40 \mathrm{ml}$ \\
\hline
\end{tabular}

C) Preparation of Mosquito repellent Gel: Preparation of mosquito repellent gel with the help of gel base and emulsion.

Table 10: Formulation of Mosquito Repellent Gel

\begin{tabular}{|l|l|l|}
\hline S. No. & Chemicals & Quantity \\
\hline 1 & Prepared gel & $40.5 \mathrm{gm}$ \\
\hline 2 & Emulsion & $7.5 \mathrm{ml}$ \\
\hline 3 & Distilled water & q.s \\
\hline
\end{tabular}

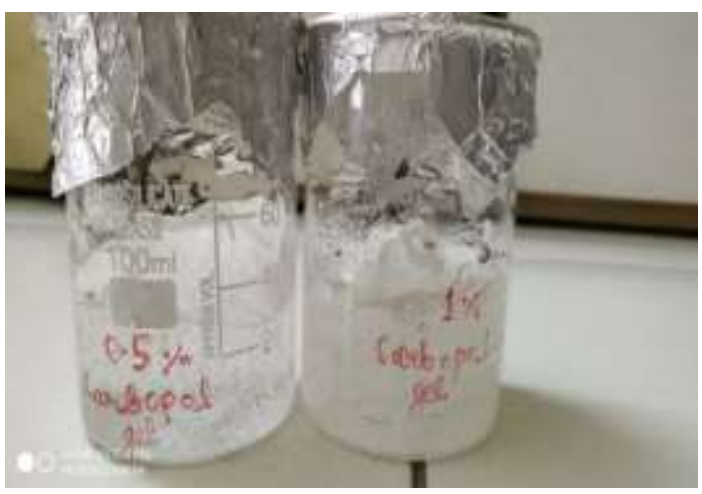

Figure 6: Gel base

\section{EVALUATION OF GELS:}

A) Clarity: The Carbopol 934 gels were found to be gleaming and clear. There were no particles in any of the gels at all shown in Table 11.

Table 11: Clarity of Gel

\begin{tabular}{|l|l|l|}
\hline S. No. & Formulation & Clarity \\
\hline 1 & Mosquito repellent gel $(0.5 \%)$ & ++ \\
\hline 2 & Mosquito repellent gel (1.0\%) & +++ \\
\hline 3 & Mosquito repellent gel (1.5\%) & ++ \\
\hline \multicolumn{2}{|l}{ Note: + Satisfactory, + + Good, + + + Excellent }
\end{tabular}

B) pH: All Carbopol gel formulations tested had $\mathrm{pH}$ values ranging from 6.3 to 6.38 (shown in Table 12).

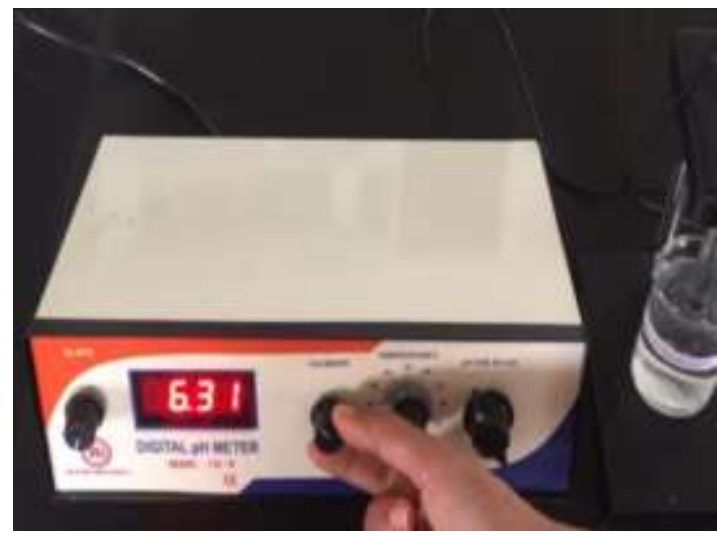

Figure 7: pH study of gel

Table 12: pH of Gel

\begin{tabular}{|l|l|l|}
\hline S. No. & Formulation & $\mathbf{p H}$ \\
\hline 1 & Mosquito repellent gel $(0.5 \%)$ & 6.31 \\
\hline 2 & Mosquito repellent gel $(1.0 \%)$ & 6.38 \\
\hline 3 & Mosquito repellent gel $(1.5 \%)$ & 6.45 \\
\hline
\end{tabular}

C) Homogeneity: There were no lumps in any of the created materials. The final products were significantly clearer and more transparent.

Table 13: Homogeneity of Gel

\begin{tabular}{|l|l|l|}
\hline $\begin{array}{l}\text { S. } \\
\text { No. }\end{array}$ & Formulation & Homogeneity \\
\hline 1 & Mosquito repellent gel $(0.5 \%)$ & Good \\
\hline 2 & Mosquito repellent gel $(1.0 \%)$ & Good \\
\hline 3 & Mosquito repellent gel (1.5\%) & Good \\
\hline
\end{tabular}

D) Spreadability: The value of spreadability indicates that the gel is easily spreadable by small amount of shear. Spreadability of Carbopol 934 in the range $18.76-25.56$ g.cm/sec indicating Spreadability of Carbopol 934 containing mosquito repellent gel was good (shown in Table 14). 


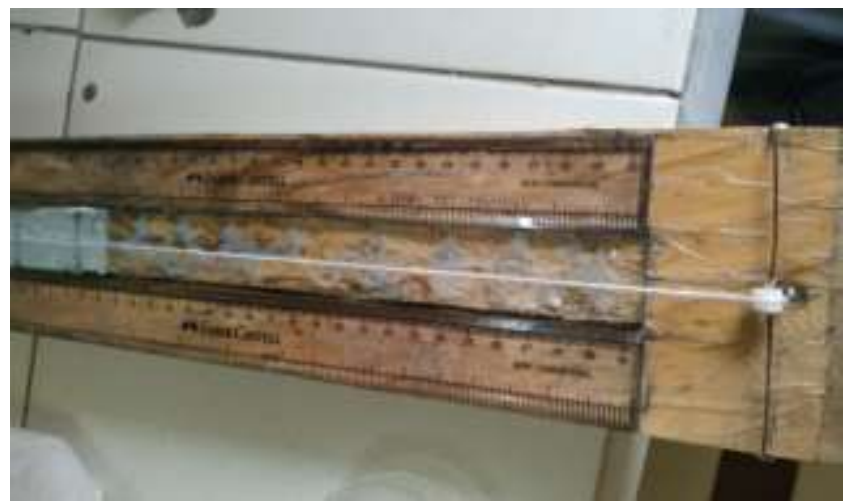

Figure 8: Spreadibility study of gel

Table 14: Spreadability of Gel

\begin{tabular}{|l|l|l|}
\hline S. No. & Formulation & Spreadability \\
\hline 1 & Mosquito repellent gel (0.5\%) & 18.76 \\
\hline 2 & Mosquito repellent gel (1.0\%) & 21.76 \\
\hline 3 & Mosquito repellent gel (1.5\%) & 25.65 \\
\hline
\end{tabular}

E) Viscosity measurement: The viscosity of formulated mosquito repellent gel was measured using a Brookfield viscometer. The rheological behavior of all formulated gels systems was studied. In gel system, consistency depends on the ratio of solid fraction, which produces the structure to liquid fraction. Viscosity of formulated mosquito repellent gels was found in range of 4456-4776 centipoises.
Table 15: Viscosity of Gel

\begin{tabular}{|l|l|l|}
\hline S. No. & Formulation & Viscosity \\
\hline 1 & Mosquito repellent gel (0.5\%) & 4776 \\
\hline 2 & Mosquito repellent gel (1.0\%) & 4456 \\
\hline 3 & Mosquito repellent gel (1.5\%) & 4567 \\
\hline
\end{tabular}

F) Extrudability: The extrusion of the gel from the tube is an important during its application and in patient acceptance. Gels with high consistency may not extrude from tube whereas, low viscous gels may flow quickly, and hence suitable consistency is required in order to extrude the gel from the tube. Carbopol gel compositions were found to have good extrudability.

\section{Table 16: Extrudability of Gel}

\begin{tabular}{|l|l|l|}
\hline S. No. & Formulation & Extrudability \\
\hline 1 & Mosquito repellent gel (0.5\%) & ++ \\
\hline 2 & Mosquito repellent gel (1.0\%) & +++ \\
\hline 3 & Mosquito repellent gel (1.5\%) & ++ \\
\hline \multicolumn{2}{|l}{ Note: + Satisfactory, ++ Good, ++ + Excellent }
\end{tabular}

G) Mosquito Repellent Bioassay: The number of mosquitoes that aligned/left and aligned/bit the participants' treated portions of legs within 6 hours is shown in Table 17.

Table 17: Repellency Bioassay

\begin{tabular}{|l|l|l|l|}
\hline Sample name & Sample C*** & Normal Control & Positive Control \\
\hline Time (min) & Repellency (\%) \pm Mean SD & Repellency (\%) \pm Mean SD & Repellency (\%) \pm Mean SD \\
\hline 0 & $0.0 \pm 0.00$ & $0.0 \pm 0.00$ & $0.0 \pm 0.00$ \\
\hline 15 & $0.0 \pm 0.00$ & $0.0 \pm 0.00$ & $40.66 \pm 2.89$ \\
\hline 30 & $14.0 \pm 7.63$ & $4.0 \pm 0.00$ & $65.33 \pm 2.86$ \\
\hline 45 & $20.0 \pm 5.00$ & $4.0 \pm 0.00$ & $95.0 \pm 0.00$ \\
\hline 60 & $51.0 \pm 2.44$ & $4.0 \pm 0.00$ & $100.0 \pm 0.00$ \\
\hline
\end{tabular}

Positive control $=$ Transfluthrin conc. $(0.88 \% \mathrm{w} / \mathrm{w})$ (Dose $=10 \mu \mathrm{l} / \mathrm{ml}$ on cardboard sheet $)$

***SAMPLE C CARDBOARD SIZE: L x B= 2.9 x $2.4 \mathrm{cms}$

H) Stability Studies: The drug content was analyzed and there was a marginal difference between the formulations stored at different temperatures as shown in Table 18. Mosquito repellent gel formulations retained good stability throughout the study.

\section{Table 18: Stability Studies}

\begin{tabular}{|l|l|l|l|l|}
\hline Parameters & Initial & $\begin{array}{l}\mathbf{1} \\
\text { month }\end{array}$ & $\begin{array}{l}\mathbf{2} \\
\text { months }\end{array}$ & $\begin{array}{l}\text { 3 } \\
\text { months }\end{array}$ \\
\hline $\mathrm{pH}$ & 6.38 & 6.35 & 6.33 & 6.30 \\
\hline Spreadability & 21.76 & 21.74 & 21.70 & 21.70 \\
\hline Viscosity & 4456 & 4450 & 4448 & 4446 \\
\hline
\end{tabular}

\section{CONCLUSION:}

Based on the findings of this study, proper essential oil selection was a requirement for creating and creating a mosquito repellent. According to the IR investigations, the polymer chosen, Carbopol 934, was proven to be compatible with the necessary Mosquito repellent gel. The $\mathrm{pH}$, viscosity and spredability, of the gel were found to be affected by different polymer concentrations. When Mosquito repellent gel Carbopol 934 is used with essential oil, patients experience better and faster results. The rate of penetration is increased by increasing the concentration of essential oil to its optimum concentration.

ACKNOWLEDGEMENT: The author is thankful with deepest core of heart to Mr. Rohit Kumar Bijauliya (Assistant 
Professor), BIU College of Pharmacy, Bareilly International University, Bareilly for his valuable guidance.

\section{CONFLICT OF INTEREST: Nil}

\section{REFERENCES:}

1. Imeda C, Katani S, Kitu A, Kitufe N, Magesa S, Magogo F, Malebo $\mathrm{H}$, Wiketye V: Repellence effectiveness of essential oils from some Tanzanian Ocimum and Hyptis plant species against afrotropical vectors of malaria and lymphatic filariasis. Journal of Medicinal Plants Research 2013; 7:653-660

2. Makhaik M, Naik SN, Tewary DK: Evaluation of anti-mosquito properties of essential oils. Journal of Scientific and Industrial Research 2005; 64:129-133

3. Adeogun AO, Adewuyi GO, Etatuvie SO, Fawehinmi AB, Lawa HO: Bioassay of Herbal Mosquito Repellent Formulated from the Essential Oil of Plants. Journal of Natural Products 2012; 5:109115

4. Mohomed AA, Tarek IAAM, Zarrag IAA: Larvicidal and repellent effect of some Tribulus terrestris L., (Zygophyllaceae) extracts against the dengue fever mosquito, Aedes aegypti (Diptera: Culicidae). Journal of Saudi Chemical Society 2012: 1-7.

5. Ranasinghe MSN, Arambewela $L$ and Samarasinghe S: Development of Herbal Mosquito Repellent Formulations. Int J
Pharm Sci Res 2016; 7(9): 3643-48. https://doi.org/10.13040/IJPSR.0975-8232.7(9).3643-48

6. Shivhare UD, Jain KB, Mathur VB et al. Formulation development and evaluation of diclofenac sodium gel using water soluble polycrylamide polymer. Digest Journal of Nanomaterials and Biostructures 2009; 4:285-290

7. Charles M. Heard, Simon J. Ketoprofen release from permeation across \& rheology of simple gel formulation that stimulate increasing dryness; Int. Journal of pharmaceutics, 2003; 268:3745 https://doi.org/10.13040/IJPSR.0975-8232.7(9).3643-48

8. Bettini, P. L. Catellani, P. Santi, G. Massimo Translocation of drug particles in HPMC matrix gel layer: effect of drug solubility and influence on release rate, Journal of Controlled Release, 2001: 70(3):383-391. 8232.7(9).3643-48

9. Guterres Silvia S, Marta P. Alves. Human skin penetration \& distribution of Nimesulide from hydrophilic gels containing nanocarriers, Int. journal of pharmaceutics, 2007; 341:215-220. https://doi.org/10.13040/IJPSR.0975-8232.7(9).3643-48

10. Alberto B. Clinical pharmacokinetics \& metabolism of Nimesulide. Inflammo Pharmacology, 2001; 9:81-89. https://doi.org/10.1163/156856001300248353 